\title{
UAV-SfM 4D mapping of landslides activated in a steep terraced agricultural area
}

\author{
Luca Mauri, ${ }^{1}$ Eugenio Straffelini, ${ }^{1}$ Sara Cucchiaro,,${ }^{1,2}$ Paolo Tarolli ${ }^{1}$ \\ ${ }^{1}$ Department of Land, Environment, Agriculture and Forestry, University of Padova, Legnaro (PD); ${ }^{2}$ Department of \\ Agricultural, Food, Environmental and Animal Sciences, University of Udine, Italy
}

\begin{abstract}
The presence of roads is closely linked with the activation of land degradative phenomena such as landslides. Factors such as ineffective road management and design, local rainfall regimes, and specific geomorphological elements actively influence landslide occurrence. In this context, recent developments in digital photogrammetry (e.g., Structure from Motion; SfM) paired with Uncrewed Aerial Vehicles (UAV) systems increase our possibilities to realize low-cost and recurrent topographic surveys. This can lead to the development of multi-temporal (hereafter: 4D) and high-resolution Digital Elevation Models (DEMs), which are fundamental to analyse geomorphological features and quantify processes at the fine spatial and temporal resolutions at which they occur. This research proposes a multi-temporal comparison of the main geomorphometric indicators describing a landslide-prone terraced vineyard to assess the observed high-steep slope failures. The possibility to investigate the evolution of landslide geomorphic features in steep agricultural systems through a high-resolution and 4D comparison of such indicators is still a challenge to be explored. In this article, we considered a case study located in the central Italian Alps, where two landslides were activated below a rural road within a terraced agricultural system. The dynamics of the landslides were monitored by comparing repeated DEMs (DEM of difference), which reported erosion values of above $20 \mathrm{~m}^{3}$ and $10 \mathrm{~m}^{3}$ for the two landslide zones and deposition values of more than $15 \mathrm{~m}^{3}$ and $9 \mathrm{~m}^{3}$, respectively. The road net-
\end{abstract}

Correspondence: Luca Mauri, Department of Land, Environment, Agriculture and Forestry, University of Padova, Agripolis, viale dell'Università 16, 35020 Legnaro (PD), Italy.

E-mail: luca.mauri.2@phd.unipd.it

Key words: Landslides; roads; agricultural systems; Uncrewed Aerial Vehicles; Geographical Information System.

Acknowledgements: the authors kindly thank Gabriele Bombardelli Acetaia del Balsamico Trentino-, owner of the terraced vineyard considered in the investigation of the observed land degradation processes.

Received for publication: 15 October 2020.

Accepted for publication: 28 December 2020.

${ }^{\circ}$ Copyright: the Author(s), 2021

Licensee PAGEPress, Italy

Journal of Agricultural Engineering 2021; LII:1130

doi:10.4081/jae.2021.1130

This article is distributed under the terms of the Creative Commons Attribution Noncommercial License (by-nc 4.0) which permits any noncommercial use, distribution, and reproduction in any medium, provided the original author(s) and source are credited. work's role in the alteration of superficial water flows was proved by the elaboration of the relative path impact index. Altered water flows were expressed by values between $2 \sigma$ and $4 \sigma$ close to the collapsed surfaces. The increase in profile curvature and roughness index described the landslides evolution over time. Finally, the multi-temporal comparison of feature extraction underlined the geomorphological changes affecting the study area. The accuracy of features extraction was analysed through the quality index computation, expressed in a range between 0 (low accuracy) and 1 (high accuracy), and proved to be equal to $0.22 \mathrm{~m}$ (L1-pre), $0.63 \mathrm{~m}$ (L1-post), and $0.69 \mathrm{~m}$ (L2). Results confirmed the usefulness of high-resolution and 4D UAV-based SfM surveys to investigate landslides triggering due to the presence of roads at hillslope scale in agricultural systems. This work could be a useful starting point for further studies of landslide-susceptible zones on a wider scale to preserve the quality and the productivity of affected agricultural areas.

\section{Introduction}

Several factors cause land degradation in agriculture, e.g., i) human pressure (Salvati et al., 2015); ii) land use and land cover changes (Bajocco et al., 2012); and iii) climate changes (Webb et al., 2017). In particular, hydro-erosive dynamics and their evolution into more complex phenomena, such as landslides, are typical land degradation processes and landform-shaping phenomena affecting cultivated lands with severe economic and environmental costs. Among the anthropogenic factors that significantly impact surface erosion and landslides, road construction plays an important role. Indeed, landslide activation and the presence of roads are strongly connected (Sidle and Ziegler, 2012). Road construction has a primary influence on landslide activation, especially in steep zones, for example, through the reduction of the slope terrain stability, the increase of slope on fill and cut surfaces, and the alteration of hydrological processes (Eker and Aydin, 2014). Moreover, the increase of road networks leads to significant changes in drainage system networks and sediment dynamics (Persichillo et al., 2018), representing a predisposing factor for greater susceptibility to landslide activation.

Despite their usefulness, the negative impacts of roads on agriculture are well documented, especially in terms of environmental and geomorphological issues (Sidle and Ziegler, 2012). Human interventions through farming practices (Bordoni et al., 2019), specific environmental conditions, and land abandonment processes could affect the conservation of terraced cultivated zones, activating landslide phenomena.

In detail, factors like surface topography, land cover and management, soil erodibility and geological characteristics, as well as rain intensity and the concentration of surface water flows along a preferential path (Lanni et al., 2012) are the factors that play a primary role in landslide activation. Meanwhile, sediments discharged 
from roads during rainfall events can seriously increase channel erosion and landslide occurrence (Sidle et al., 2006). Indeed, the presence of roads in agriculture alters the water flow directions through: i) the interception of superficial and sub-surface water flows; ii) the concentration of flows on the road itself; and iii) the modification of already present flow directions (Borga et al., 2004). Therefore, since topography plays a direct role in landslide activation, especially in steep slopes, continuous monitoring of the landscape evolution through geomorphological indicators could provide important information on the road-landslide dynamics. In this context, recent developments in digital photogrammetry (e.g., Structure from Motion; $\mathrm{SfM}$ ) together with Uncrewed Aerial Vehicles (UAVs) have increased our possibilities to conduct low-cost and recurrent topographic surveys of the Earth surface. Compared to other techniques, such as Light Detection And Ranging (LiDAR), the SfM technique combined with multi-view stereo (MVS) algorithms (hereafter together referred to as SfM) allow us to obtain a high-quality and cost-effective $3 \mathrm{D}$ reconstruction of an object starting from a series of twodimensional images, taken from different points of view (Westoby et al., 2012). Furthermore, it is interesting to evaluate the use of these technologies in the continuous monitoring of landslides in agricultural contexts and investigate the interaction between the presence of infrastructures such as roads and the activation of instability phenomena. High-resolution terrain reconstruction at a detailed scale can be performed through SfM application to carry out an accurate analysis of geomorphological processes involving landslide-prone areas over time. Starting from UAV-SfM data, the multi-temporal comparison of geomorphometric indicators, such as roughness, landform curvature, and feature extraction in landslide-prone zones, can be performed.
The continuous development that characterizes these technologies offers countless opportunities for future applications, launching new challenges in different fields. In light of the above, this research proposes a detailed integrated multi-temporal analysis of geomorphological changes involving a terraced vineyard affected by landslides activated near a road network. Multi-temporal (hereafter: 4D) and high-resolution digital elevation models (DEMs) were used to assess the dynamic of landslide geomorphic features after two subsequent failure events. While the multitemporal survey has already been carried out for deep-seated landslides monitoring, large-scale subsidence or mining activities, its application in high-steep agricultural context to detect the changes of shallow landslide features, activated even by roads, is absolutely novel. More in detail, the geomorphic feature extraction, based on detection of thresholds derived by statistical analysis of landform curvature variability, has been proposed considering a single survey, therefore without addressing multitemporal extraction (Tarolli et al., 2012). Thus, the UAV-based multi-temporal monitoring of shallow landslide features (e.g., crowns) dynamics over time represents a further novel aspect of our work. Finally, the proposed research fills the gap in scientific knowledge regarding the possibility of efficiently analysing landslide evolution in agricultural systems by comparing these geomorphometric indexes at hillslope scale, adopting a flexible, low-cost, yet accurate approach.

\section{Study area}

The study area is located in the Trento province, in the southern part of the Trentino Alto Adige region, in northern Italy (Figure 1A). It has an extension of 2.2 ha, with a southwest aspect, an aver-

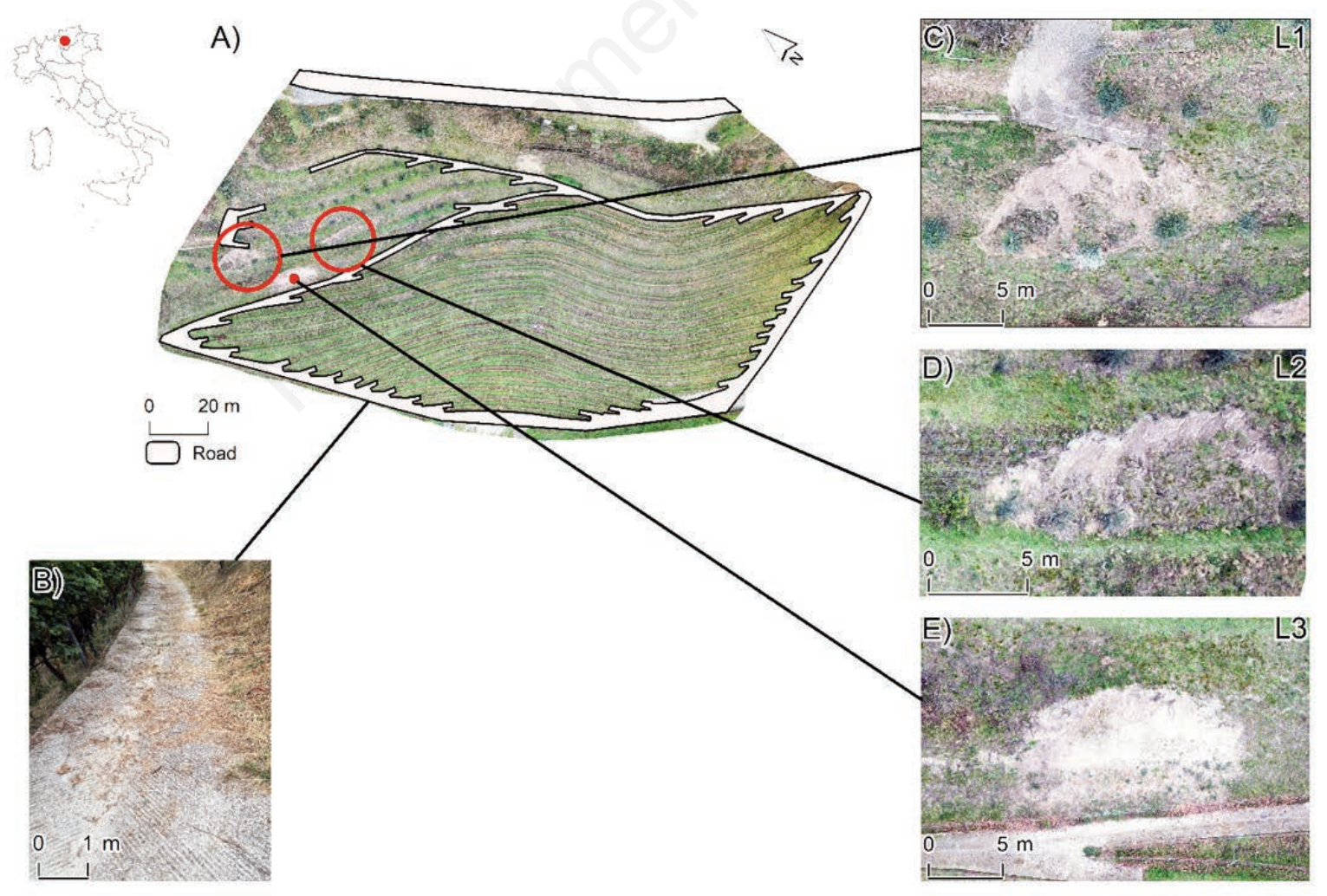

Figure 1. Overview of the entire study area (A) and focus on landslides detected during Uncrewed Aerial Vehicles-Structure from Motion surveys. In particular, this figure shows the paved road surface (B), the first observed landslide (L1, C), the second landslide (L2, D), and the third observed collapsed surface $(\mathrm{L3}, \mathrm{E})$. 
age slope of $27.6^{\circ}$, and an average elevation of $287 \mathrm{~m}$ a.s.l. (elevation range between a minimum of $266 \mathrm{~m}$ a.s.l. downstream and a maximum of $320 \mathrm{~m}$ a.s.l. on the top). The annual average rainfall based on 20-year average values from 10 local stations close to the study area is equal to $1088 \mathrm{~mm}$, with a standard deviation of 222 $\mathrm{mm}$ that identifies notable inter-annual rainfall variations. The study area is characterized by terraces constructed on steep slopes (average slope equal to 27.49 degrees) using earth banks, with an inter-row grass cover on the entire cultivated surface. In the study area, three shallow landslides were detected during the two field surveys. The first (18 October 2019) identified a first landslide (L1) below a specific section of the road located in the vineyard (Figure 1C) and another zone involved in older terrain failures (L3, Figure 1E). During the second survey (17 December 2019), an evolution of the L1 zone was observed, with significant involvement of the L1 area. Finally, a further landslide (L2, Figure 1D), about $20 \mathrm{~m}$ away from the first, was detected. Factors like steep slopes and high rainfall rates potentially triggered such terrain failures. In this regard, a local weather station recorded an intensity peak equal to $33.6 \mathrm{~mm} \mathrm{~h}^{-1}$ and other rain events with lower-intensity but longer duration during the weeks preceding the days when the landslides were probably activated, with average values between 0.4 and $1.3-\mathrm{mm} \mathrm{h}^{-1}$, and rainfall duration between 5 and 11 hours.

In addition to this, the presence of the road network within the study area can be considered as an additional element, which was potentially responsible for the observed terrain failures. The road was made to reach the highest sections of the vineyard to facilitate some agricultural activities. The road's surface is partly made of concrete (Figure 1B) with some unpaved sections in the whole vineyard. The total length of the road network inside the study area is about $600 \mathrm{~m}$ with an average width of about $2 \mathrm{~m}$, on an average slope of $15.7^{\circ}$ (slope range between a minimum of $0.03^{\circ}$ and a maximum of $19.2^{\circ}$ ).

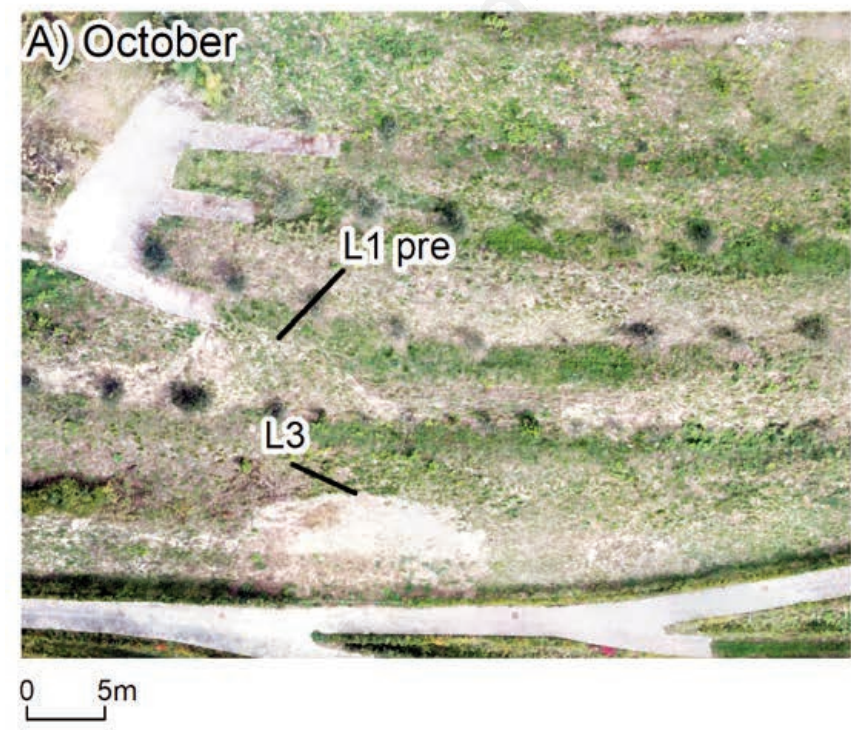

\section{Materials and methods}

\section{Data collection and processing}

\section{Landslide overview within the study area}

During field inspections, the extension and the thickness of the soil removed by the landslides were measured manually with a stick meter to have an initial overview of their characteristics. The measures taken on the field firstly underlined an increased extension of the L1 surface of more than $50 \mathrm{~m}^{2}$ (Figure 2). The measurements of the vertical distance between the top of L1 and the ground below were calculated manually during the first and the second survey and were equal to a maximum value of $0.85 \mathrm{~m}$ and $1.20 \mathrm{~m}$, respectively. The length of the road section located at the top of L1 was $11.8 \mathrm{~m}$, and L1 was characterized by an average slope of above 38 degrees, covering a surface of $44 \mathrm{~m}^{2}$ and a perimeter of above $34 \mathrm{~m}$. The measurements of L2 revealed an average slope of 40.9 degrees, a surface of more than $60 \mathrm{~m}^{2}$, a perimeter of about 40 $\mathrm{m}$, and a maximum vertical distance (between its crown and the ground below) equal to $1.10 \mathrm{~m}$. Finally, the characteristics of the third observed failure (L3) did not change between the first and the second UAV survey, with a corresponding surface of $98 \mathrm{~m}^{2}$, a perimeter of about $45 \mathrm{~m}$, an average slope of 43.4 degrees, and a maximum vertical distance equal to $0.90 \mathrm{~m}$. Considering that, the proposed analysis investigated the land degradation dynamics affecting L1 and L2 zones over time.

\section{Uncrewed Aerial Vehicles-Structure from Motion data acquisition}

4D UAV-SfM surveys were carried out to compare and detect the differences in topographical and geomorphological terms for the detected landslide. Ground control points (GCPs) and checkpoints (CPs) were considered as an integral part of the process to reduce errors significantly and check the quality of the output. Particular attention was paid to the location of visible GCPs and CPs in the study area, making sure they were uniformly distributed.

Figure 2. Comparison between landslides detected during the first Uncrewed Aerial Vehicles (UAV) survey (A: 18 October 2019) and

the second one (B: 17 December 2019). Both aerial photos were taken during field surveys with UAV.

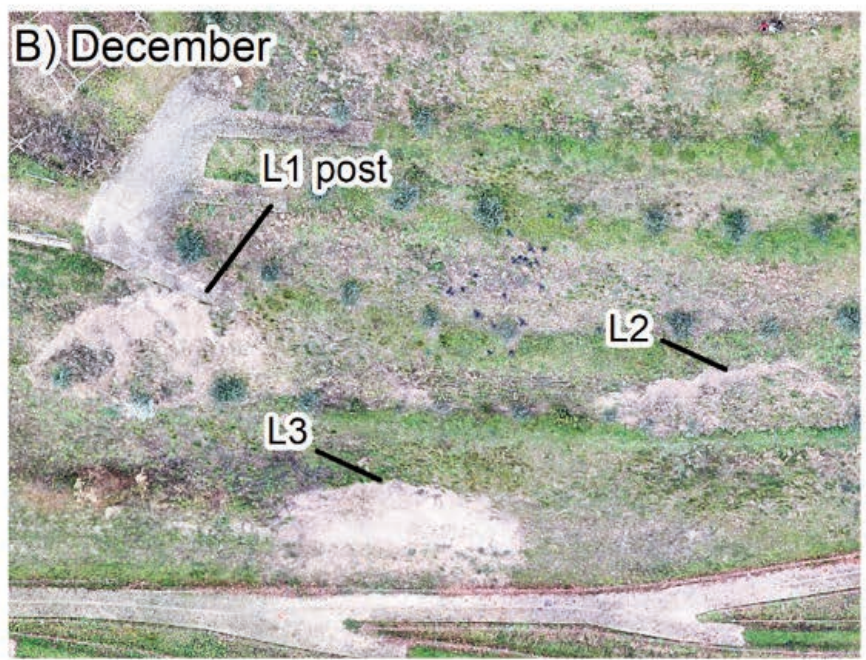


Two UAV-SfM surveys were conducted on 18 October 2019 and 17 December 2019, respectively, after two subsequent landslide events. Each survey was planned on days with similar weather conditions and at the same time of day to preserve the quality of the SfM survey. Photos were taken with a DJI Mavic Pro ${ }^{\circledR}$ UAV, which mounts a camera with $1 / 2.3$ " sensor (CMOS), focal length $26 \mathrm{~mm}, 12 \mathrm{M}$ pixel, and a stabilized 3-axes gimbal. The GCPs and CPs were measured using the Geomax Zenith $40^{\circledR}$ GNSS receiver in RTK mode (WGS 84/UTM zone 32N coordinate system; EPSG 32632). To achieve an optimal aerial image overlap and for the subsequent generation of photogrammetric outputs, a detailed flight mission planning is fundamental before image acquisition. In this way, the main parameters concerning both the flight (e.g., speed and altitude of the drone) and the camera (e.g., gimbal tilt and image format) were carefully set. Since the flight altitude is related to the take-off point, the survey was divided into different parts, considering the altitude differences in the entire study area. Nadiral and oblique photographs were integrated to have a complete survey of the vertical (e.g., terrace walls) and horizontal (flat terrace areas) features of the study area. Finally, the surveys were integrated with pictures taken in manual flight mode. In this way, it was possible to focus on specific zones (e.g., the detected landslides) and increase the quality of the outputs significantly.

Regarding the first UAV-SfM survey performed, a total of 464 images were taken on a surface of 2.22 ha at a flight altitude of $46 \mathrm{~m}$. The second UAV-based survey covered an equivalent surface at the same altitude, taking a total of 515 images. A total of 23 GCPs and 10 CPs were located among the study area and measured with the GNSS receiver, with an X, Y-Z accuracy between 0.03 and $0.04 \mathrm{~m}$.

\section{Structure from Motion data processing}

UAV images were processed using the software Agisoft Metashape Pro ${ }^{\circledR}$ v 1.6.2., which makes it possible to reconstruct a three-dimensional model of a surface based on SfM and MVS algorithms. In particular, the procedure included the fundamental steps, i.e., i) camera pre-calibration and removal of low-quality images; ii) SfM step that aligned photos and created a sparse points cloud; iii) GCPs addition for point cloud georeferencing and respective error evaluation; iv) point cloud optimization through a bundle adjustment algorithm; v) elaboration of high-density point cloud; vi) orthomosaic generation.

To identify any bias and estimate the accuracy and precision of the obtained point clouds, 1/3 of GCPs were selected and considered as CPs, excluding them in the data georeferencing process (Cucchiaro et al., 2018). In this way, an analysis of GCPs and CPs residuals (e.g., the difference between the real coordinates of this point and the modelled values) provide a measure of uncertainty of each point cloud. The mean of the residuals indicates the accuracy of the registration process; the standard deviation of the residuals yields an indication of the precision level (Cucchiaro et al., 2018).
Furthermore, the root mean square error (RMSE3D) was computed in $\mathrm{x}, \mathrm{y}$, and $\mathrm{z}$ directions to check further for potentially biased point errors (Remondino et al., 2017).

\section{Structure from Motion point cloud post-processing}

The obtained point clouds were processed using Cloud Compare software (http:/www.danielgm.net), to approach point filtering steps. In this regard, the removal of noises and outliers preserving terrain features and details were performed on both point clouds following two phases. Firstly, manual cleaning was conducted to remove all the points outside the study area, clearly defining its boundaries. Secondly, outliers were removed through the statistical outlier removal (SOR) filter, based on the point cloud library. The SOR algorithm computes the average distance between each point and its neighboring points. It rejects the points beyond a specific threshold, which is calculated based on two parameters: $k$ (i.e., the number of points to consider in the computation of the mean distance) and nSigma (i.e., the standard deviation multiplier threshold).

Subsequently, point clouds were filtered by selecting only the points belonging to the Earth's surface. This operation is crucial in DEM creation, particularly in complex areas, such as agricultural fields with dense vegetation. Despite numerous semi-automatic algorithms for extracting terrain points from clouds, manual filtering allowed us to carefully clean the point clouds. In this connection, point clouds were divided into regular sections along the line of maximum slope, creating strips and facilitating the cleaning process. Finally, a quality evaluation of the elaborated 3D point clouds was computed, looking at precision, accuracy, and registration errors through the GCPs and CPs quality assessment.

\section{Point clouds co-registration and Digital Elevation Models elab- oration}

To improve the results of the multi-temporal point clouds comparison, the co-registration step was necessary to minimize the spatial difference between them, especially regarding vertical data (i.e., the elevation value). To identify the reference point cloud and the aligned one, the RMSE3D values of GCPs and CPs were considered (Table 1). Based on these values, the point cloud of December 2019 was chosen as the reference cloud, while the point cloud of the first survey was considered as the aligned one, which was moved during the co-registration procedure. Point clouds coregistration was performed in Cloud Compare, using the Point Pairs Picking tool. Manholes located along the road network around the vineyard were considered as specific stable point pairs in both point clouds to align. An error analysis was computed by looking at the multiscale model to model cloud comparison (M3C2) distance calculation during the cloud-to-cloud comparison (Lague et al., 2013), considering the standard deviation of M3C2 value as precision error for stable areas.

Table 1. Main errors in the Structure from Motion surveys point clouds.

\begin{tabular}{|c|c|c|c|c|c|c|c|c|c|}
\hline \multirow[t]{2}{*}{ Point cloud } & \multirow{2}{*}{$\begin{array}{l}\text { Point cloud } \\
\text { (number of points) }\end{array}$} & \multicolumn{3}{|c|}{ Point cloud accuracy (m) } & \multicolumn{3}{|c|}{ Point cloud precision (m) } & \multirow{2}{*}{$\begin{array}{l}\text { RMSE3D } \\
\text { CPs (m) }\end{array}$} & \multirow{2}{*}{$\begin{array}{l}\text { RMSE3D } \\
\text { GCPs (m) }\end{array}$} \\
\hline & & $\mathbf{x}$ & y & $\mathrm{z}$ & $\mathrm{x}$ & y & $\mathbf{z}$ & & \\
\hline $\begin{array}{l}\text { Survey } 1 \\
\text { (18 October 2019) }\end{array}$ & $78,940,480$ & 0.040 & 0.020 & 0.035 & 0.020 & 0.026 & 0.037 & 0.057 & 0.039 \\
\hline $\begin{array}{l}\text { Survey } 2 \\
\text { (17 December 2019) }\end{array}$ & $67,120,287$ & 0.017 & 0.016 & 0.038 & 0.014 & 0.012 & 0.026 & 0.046 & 0.039 \\
\hline
\end{tabular}

The table shows the number of points of the two computed dense point clouds, point cloud accuracy [described by the absolute mean of check points (CPs) residuals] and point cloud precision (described by standard deviation of CPs residuals) for the two Uncrewed Aerial Vehicles surveys, and root mean square error (RMSE3D) total value observed during point cloud elaboration, respectively regarding ground control points (GCPs) and CPs. 
Finally, the elaboration of DEMs was carried out considering the Natural Neighbour Interpolation technique. Based on a subset of surrounding points, it provides a value to the unknown point according to the weight assigned to each one as a function of a proportional area. Subsequently, the interpolation was performed using ArcGIS ${ }^{\circledR}$ software, setting a DEM cell size of $0.15 \mathrm{~m}$ to identify specific geomorphological changes and surface alterations. An analysis of DEMs accuracy was carried out, focusing on the discrepancies between the CPs elevation measurements detected with the GNSS and the corresponding DEM values so as to calculate the RMSE for each digital elevation model.

\section{Morphometric analysis of landslides}

\section{Relative Path Impact Index}

Considering the aims of this research, it is fundamental to better understand if the road's presence plays a potential role in the activation of the observed landslides.

To quantify the influence of the road on the alteration of surface flow directions, the relative path impact index (RPII) was applied (Tarolli et al., 2013), investigating the possibility of adopting this method also in a terraced agricultural area. The RPII, mathematically defined by Equation 1, is a morphological index that can compute the effects of specific anthropogenic elements (e.g., roads and trails) on the distribution of the contributing area and hence of the flow pathways. In particular, the contributing area is considered a proxy of the distribution of the flow paths. The logarithmic form of the index better underlines the zones with an increase of the drainage area due to the road presence.

$$
R P I I=\ln \left(\frac{A_{r}-A_{s m}}{A_{s m}}\right)
$$

Considering the equation above, $A_{r}$ stands for the contributing area evaluated in the presence of the road network, while $A_{s m}$ represents the contributing area elaborated without any road through a specific DEM smoothing process. In this regard, the drainage areas were calculated following the methodology proposed in Tarolli et al. (2013) using the D-Infinity flow direction algorithm. The DEM derived from the first UAV survey was considered in order to focus on the predictive role of RPII in the detection of any alteration of road-induced flow directions. Therefore, the considered DEM was smoothed applying the quadratic approximation introduced by Evans (1979), as underlined in the following Equation (2):

$$
Z=a x^{2}+b y^{2}+c x y+d x+e y+f
$$

where $x, y$, and $Z$ are local coordinates and parameters $a$ to $f$ stand for the quadratic coefficients, solved by applying a 91-m moving window to correctly simulate the absence of infrastructures (i.e., the road network). In our case, looking at both DEM resolution and road size, this turned out to be the most appropriate value able to correctly smoothen the considered DEM and avoid excessive reductions in the extent of the terrain elevation model, as a consequence of the smoothing operations. The RPII values are directly proportional to the alteration of flow paths due to the presence of specific anthropogenic features (Tarolli et al., 2013).

\section{Quantification of morphological changes through Digital eleva- tion models of Difference computation}

The geomorphological changes affecting the study area were analysed through DEMs comparison. This is possible by DEMs subtraction and calculating the total volume of erosion, deposition, and net change through the DEM of difference (DoD) elaboration. DoD was performed with the geomorphic change detection (GCD) ArcGIS $^{\circledR}$ software (Weaton et al., 2010). Due to the morphological complexity of the study area, it was not possible to use a uniform error and consequently apply a simple minimum level of detection $(\min L o D)$ for the DoD computation (Bossi et al., 2015) to achieve efficient results. In this regard, a spatial minLoD was applied to threshold correctly any significant changes (Cucchiaro et al., 2018) and evaluate spatial uncertainties in each DEM. The multiple error assessment method was performed based on the different types of surfaces in the study area in which the DoD was computed. The various surfaces were divided into stable areas, vegetation, landslides, and zones that were previously excluded in DoD computation (i.e., No Data resulting from the presence of shadows or holes in the computed clouds, as well as zones with low point density). During the DoD elaboration, error surfaces were created for each surface type, considered a specific mask with a respective error value (i.e., $0.044 \mathrm{~m}$ for the road network, 0.120 $\mathrm{m}$ for vegetation, and $0.044 \mathrm{~m}$ for landslides). Error values for the road network and landslides were calculated considering the road as a stable area. The multiscale model to model cloud comparison (M3C2) tool of cloud compare was used to define the distance between SfM point clouds in these unchanging zones. The standard deviation of $\mathrm{M} 3 \mathrm{C} 2$ distance was adopted as precision error for stable areas and landslides to correctly calculate erosion, deposition, and net change volumes. Finally, vegetated surfaces (i.e., vineyard and grass zones located around it) were considered the last surface types with error values related to the presence of residual vegetation (i.e., low foliage and residual biomass) on the ground, especially along the rows of vines. In this connection, the error value for vegetated surfaces was chosen according to the absolute mean of vertical residual noises within both vineyard and grass zones.

The computation of uncertainty values (i.e., precision errors) of each surface type was performed for the two DEM to propagate them during their comparison. The spatially distributed approach was suggested for error propagation and further identification of the final $\min L o D$ value to analyse successfully any detected geomorphological changes. The minLoD value can be calculated based on Equation (3) proposed by Brasington et al. (2003):

$$
\min L o D=t \sqrt{\left(\varepsilon_{1-i}\right)^{2}+\left(\varepsilon_{2-i}\right)^{2}}
$$

where $t$ stands for spatial distributed Student's $t$-values, while $\varepsilon_{1-i}$ and $\varepsilon_{2-i}$ stand for the errors of a specific $i$-pixel for each DEM. The final thresholded DoD was elaborated adopting a $t$-value equal to 1.96 , corresponding to a $95 \%$ confidence interval (CI) to maintain a conservative approach for the $\mathrm{DoD}$ computation.

Finally, the budget segregation function of GCD was applied to calculate the erosion and deposition volumes for specific regions of the study area, for which the DoD was elaborated (that is, focus the analysis on landslides zones). The raw DoD was computed, comparing the values of the thresholded DoD with the results of DoD elaborated avoiding the application of a specific minLoD. 


\section{Multi-temporal comparison of geomorphometric indicators}

Land morphological changes were analysed further by the computation of specific geomorphometric indicators. First, a multi-temporal comparison of the curvature and roughness index of landslide-prone areas was computed. In this work, a multi-temporal mapping of curvature changes along the landslide profile was elaborated starting from the analysis of the profile curvature, i.e., the curvature along the vertical plane in the steepest downslope direction (Krebs et al., 2015). The selection of specific kernel size in the profile curvature elaboration permitted us to depict the land surface curvature in detail. The profile curvature was calculated with a 9-cell moving window to identify precisely all convexity and concavity zones.

In addition to the multi-temporal analysis of the profile curvature, the multi-temporal comparison of the roughness index was elaborated. As underlined by Sofia (2020), the variability of surface roughness can be associated with the occurrence of gravitational processes, such as landslides and erosive phenomena. In this connection, surface roughness can be defined as the standard deviation of residual topography (Cavalli and Tarolli, 2011). Therefore, each computed DEM was smoothed within a 9-cell moving window, looking at the size of the specific features under investigation. The corresponding grid of residual topography was then created by calculating the cell-by-cell difference between the original DEM and the smoothed one. The standard deviation of residual topography was calculated considering the following Equation (4), through the application of specific codes in the GRASS GIS environment:

$$
\sigma=\sqrt{\frac{\sum_{i=1}^{n}\left(x_{i}-x_{m}\right)^{2}}{n}}
$$

where $\sigma$ stands for the roughness index, $n$ is the number of processed cells in the moving window, $x_{i}$ is the value of the $i$-cell of the residual topography within the selected moving window, and $x_{m}$ is the mean of the processed cells within the 9-cell moving window.

\section{Multi-temporal feature extraction}

To perform a multi-temporal feature extraction, the maximum curvature $\left(\mathrm{C}_{\max }\right)$ was calculated to highlight local surface convexity identified in slope discontinuities and consequently related to landslide-prone surfaces (Tarolli et al., 2012). $\mathrm{C}_{\max }$ was elaborated following the multi-scale parameterization proposed by Wood (1996). Accordingly, it is possible to evaluate $\mathrm{C}_{\max }$ using the following Equations (5 and 6):

$$
C_{\max }=-a-b+\sqrt{(a-b)^{2}+c^{2}}
$$

$$
C_{\max }=k * g\left(-a-b+\sqrt{(a-b)^{2}+c^{2}}\right)
$$

where $a, b$ and $c$ are quadratic coefficients, $g$ is the DEM grid resolution, and $k$ is the size of the selected moving window. A 9-cell moving window was chosen for $\mathrm{C}_{\max }$ computation to adequately proceed in features extraction overlooking the presence of irrelevant elements. The interquartile range (IQR) was used to define the threshold value of $\mathrm{C}_{\max }$. In particular, a threshold equal to $1.5 \mathrm{IQR}$ of $\mathrm{C}_{\max }$ was adopted as a suitable threshold for shallow landslide feature extraction, as already demonstrated in Tarolli et al. (2012), where similar shallow landslide features were considered. The following Equation (7) was adopted in the calculation:

$$
C_{\max }>m * I Q R_{C_{\max }}
$$

where $m$ is the selected multiplication factor, and $I Q R$ stands for the difference between the third and the first quartiles. LandSerf and Matlab ${ }^{\circledR}$ software packages were used for $\mathrm{C}_{\max }$ elaboration and its respective threshold evaluation. The accuracy of extracted features for both L1 and L2 was assessed, considering that the process of features classification is affected by statistical errors. After defining the null hypothesis, in this case corresponding to the condition in which the study area is not involved in landslides, it is necessary to define whether it was correctly discarded in favour of the alternative one (i.e., the presence of landslide features within the detected study area) through the feature extraction procedure. Therefore, type I error is shown if the null hypothesis is rejected, when indeed it is true. On the contrary, type II error occurs when the null hypothesis is accepted, when indeed it is false. Type I error stands for false-positive, and type II error for false negative (Tarolli et al., 2012). To verify the accuracy of the extracted features, they were compared with the features of L1 and L2 mapped and rasterized from orthophoto and field data. Considering the landslide measures collected on the field, a buffer of $1.5 \mathrm{~m}$ was created on each side of the L1, and L2 reference features, respectively, to envelope convex slope breaks and to correct issues related to horizontal accuracy misstatements of each DEM. The goodness of feature extraction was analysed by calculating the quality index (Equation 8) proposed by Heipke et al. (1997):

$$
\text { Quality }=\frac{T P}{T P+F P+F N}
$$

where TP are true positives (i.e., the features which are correctly detected by the extraction method), FP are false positives (defined as the extracted features that do not correspond to the field observations), and $\mathrm{FN}$ are false negatives (i.e., zones within the buffer that are not extracted by the adopted method). The quality index ranges between 0 (for no overlap between extracted and observed features) and 1 (for perfect overlap between extracted and observed features) (Tarolli et al., 2012).

\section{Results}

\section{Structure from Motion error assessment}

An overview of main parameters and errors computation of the SfM point clouds is presented in the following Table 1, which highlights the magnitude in centimetres of the overall accuracy of the SfM surveys, described by the respective GCPs and CPs errors.

The values of the $\mathrm{M} 3 \mathrm{C} 2$ distance are in centimetres, further underlining the quality of the computed analysis. The uncertainty values of each detected surface type were identified by looking at each UAV-derived point cloud (Table 2). The co-registration process was then performed to obtain a final RMS value (i.e., the coregistration error) equal to $0.045 \mathrm{~m}$. Finally, DEMRMSE was equal to $0.103 \mathrm{~m}$ and $0.058 \mathrm{~m}$, respectively, for the first and the second computed digital elevation model. 


\section{Relative Path Impact Index}

Figure 3A shows the detail of the RPII index close to the L1 location. Figure $3 \mathrm{~B}$ shows that a specific section of the road is potentially involved in alterations of the water flows and consequently in the detected geomorphological changes. Moreover, the evident alteration of the water flows located to the left of the L1 area consists of a zone that is not currently affected by land degra- dation. However, this could be potentially predictive of a worsening of the present situation in the future. Furthermore, concerning the RPII index near the L2 zone (Figure 3C), it appears that the unpaved section of the road network located above the L2 area is potentially responsible for the alterations of the shallow water flows toward the zone affected by the landslide (Figure 3D). As the figure shows, there is a marked alteration of the flow paths (iden-
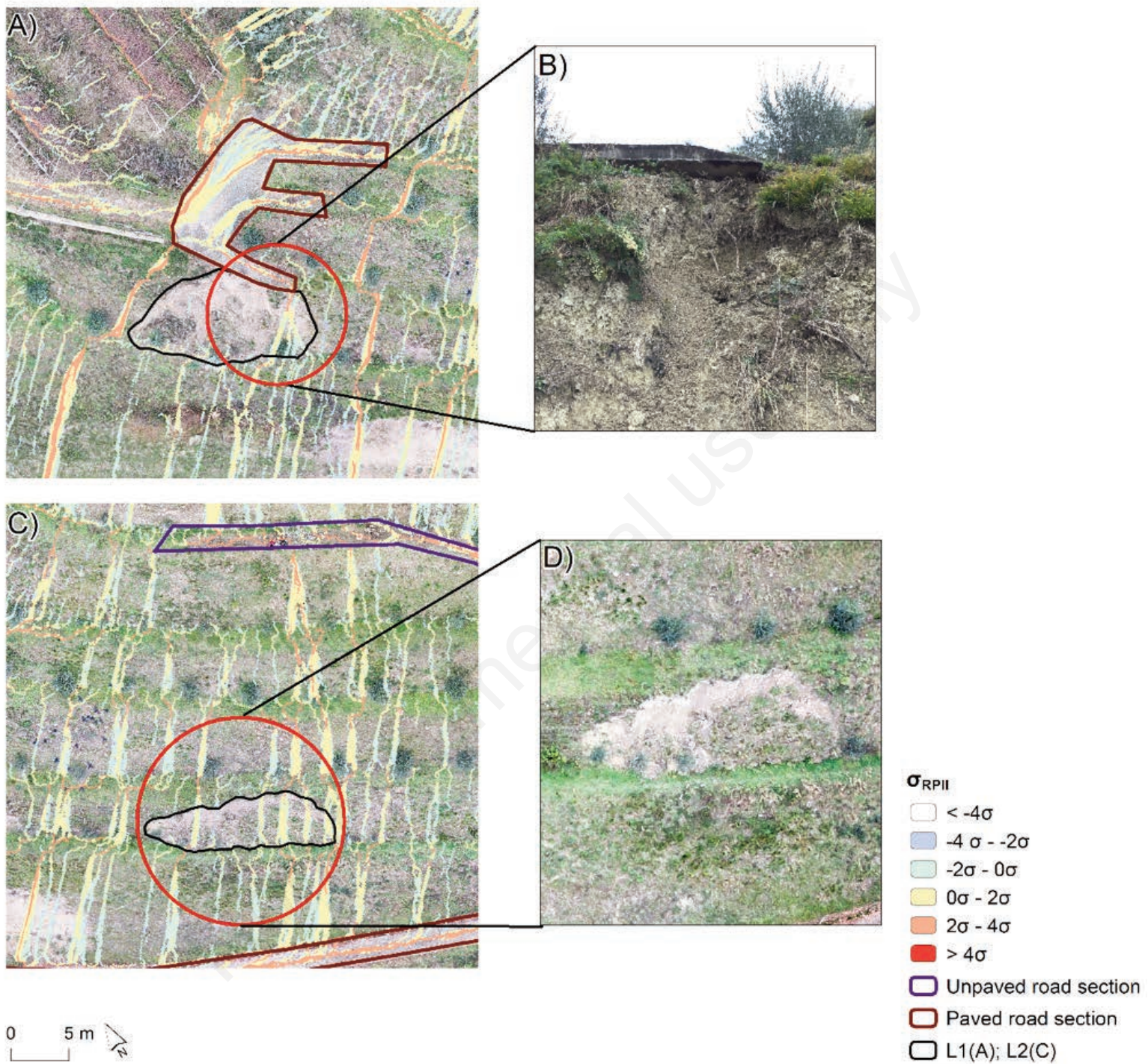

Figure 3. Detail of relative path impact index (RPII) underlining the flow alterations close to the paved section of the road, located upstream to the L1 (A) and L2 (C) zones and focus on L1 (B) and L2 (D) areas under the specific road section. Critical zones, identified by the higher $\sigma$ RPII values (reddish colours) represent the flow concentrations due to the presence of the road. In particular, the red circles highlight such alteration close to the road segment located upstream the L1 (A) and L2 zone (C).

Table 2. Detail of budget segregation results for the digital elevation models of difference (DoD) computed for L1 and L2. The table shows the results of thresholded DoD and their respective raw DoD results for each detected landslide.

\begin{tabular}{lcccccc}
$\begin{array}{l}\text { DoD } \\
\text { December 2019- } \\
\text { October 2019 }\end{array}$ & $\begin{array}{c}\text { Erosion } \\
\left(\mathrm{m}^{3}\right)\end{array}$ & $\begin{array}{c}\text { Thresholded DoD }(95 \% \mathrm{CI}) \\
\text { Deposition } \\
\left(\mathrm{m}^{3}\right)\end{array}$ & $\begin{array}{c}\text { Net volume difference } \\
\left(\mathrm{m}^{3}\right)\end{array}$ & $\begin{array}{c}\text { Erosion } \\
\left(\mathrm{m}^{3}\right)\end{array}$ & $\begin{array}{c}\text { Raw DoD Dosition } \\
\left(\mathrm{m}^{3}\right)\end{array}$ & $\begin{array}{c}\text { Net volume difference } \\
\left(\mathrm{m}^{3}\right)\end{array}$ \\
L1 & $20.49 \pm 2.29$ & $15.26 \pm 2.03$ & $-5.23 \pm 3.06$ & 21.49 & 15.64 & -5.84 \\
L2 & $10.34 \pm 1.29$ & $9.61 \pm 1.52$ & $-0.73 \pm 1.99$ & 10.69 & 9.95 & -0.74 \\
\hline
\end{tabular}

DoD, digital elevation models of difference; $\mathrm{Cl}$, confidence interval. 
tified by medium-high RPII values) starting from that section of the unpaved road upwards to intercept the L2 area and then reaching the underlying paved road. The RPII index underlines the primary role played by the presence of the road in the terraced vineyard in the alteration of the water flows, thus potentially triggering the activation of landslides.

\section{Digital elevation models of Difference}

Figure 4A illustrates the thresholded DoD (95\% CI) elaborated for the entire study area. Erosion and deposition surfaces for both L1 (Figure 4B) and L2 zones (Figure 4C) are notable, while erosion areas into the vineyard mainly derive from small residual dis- crepancies in the filtering processes. Results from budget segregation are reported in Table 2 and in the bar plots of volumetric changes (Figure 4D and E). Table 2 highlights that differences between the raw DoD values and the thresholded DoD are in the order of a few centimetres, thus showing low uncertainties in the accuracy of the volume estimation.

Considering the computed DoD, the adoption of the multiple error assessment method, whereby the DoD results are stripped according to specific error surfaces (Wheaton et al., 2010; Cucchiaro et al., 2018), allowed us to make a detailed volumetric estimation of erosion and deposition surfaces. In our case, threshold values describing the volumetric results underline the successful implementation of DoD related to the detected landslides.

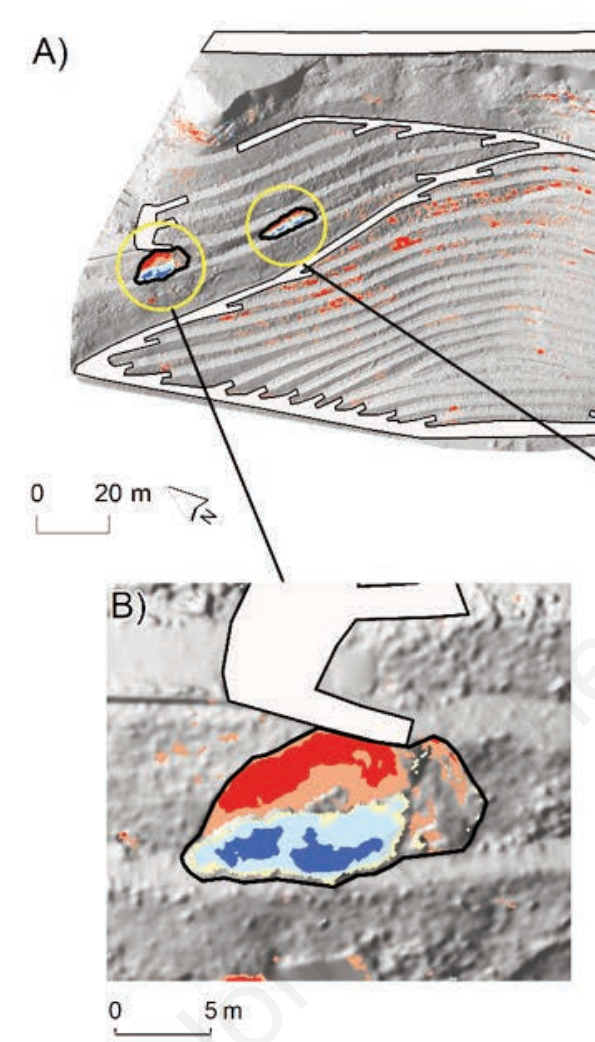

D)

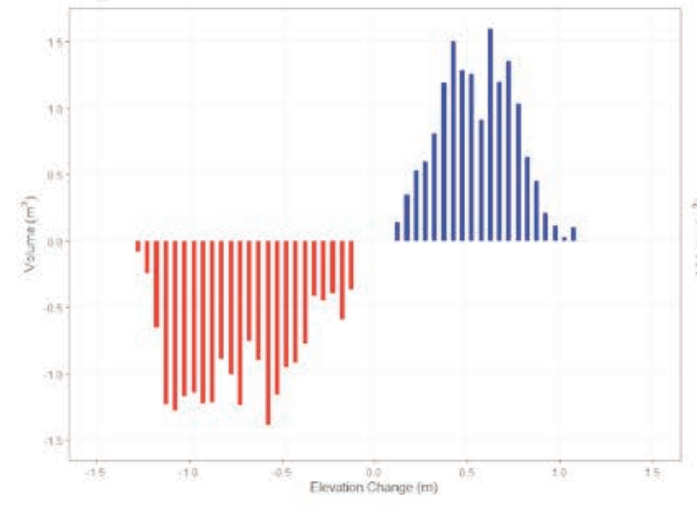

DoD

Elevation difference $(\mathrm{m})$

$-1.30--0.40$

$-0.40--0.10$

$0.10-0.30$

$0.30-0.60$

$0.60-1.10$

$\square$ Road

$\square$ Landslides

Figure 4. Overview of the computed digital elevation models of difference (DoD) (95\% confidence interval) (A) and focus on DoD elaborated for the L1 (B) and L2 zones (C). Erosion is shown in reddish colours, deposition in blue. The figure also shows the bar plot of elevation changes regarding volumetric erosion and deposition values derived from budget segregation results computed for the $\mathrm{L} 1$ (D) and $\mathrm{L} 2$ zones (E) respectively. 


\section{Multi-temporal comparison of geomorphometric indicators}

The computation of profile curvature for L1 and L2 zones is presented in Figure 5, which highlights the worsening of the L1 zone due to the presence of several upwardly convex surfaces (red- dish colours, Figure 5C). With reference to Wilson and Gallant (2000), net erosion areas correspond to profile convexity zones, while net deposition areas correspond to profile concavity zones. Moreover, the profile curvature is parallel to the direction of the
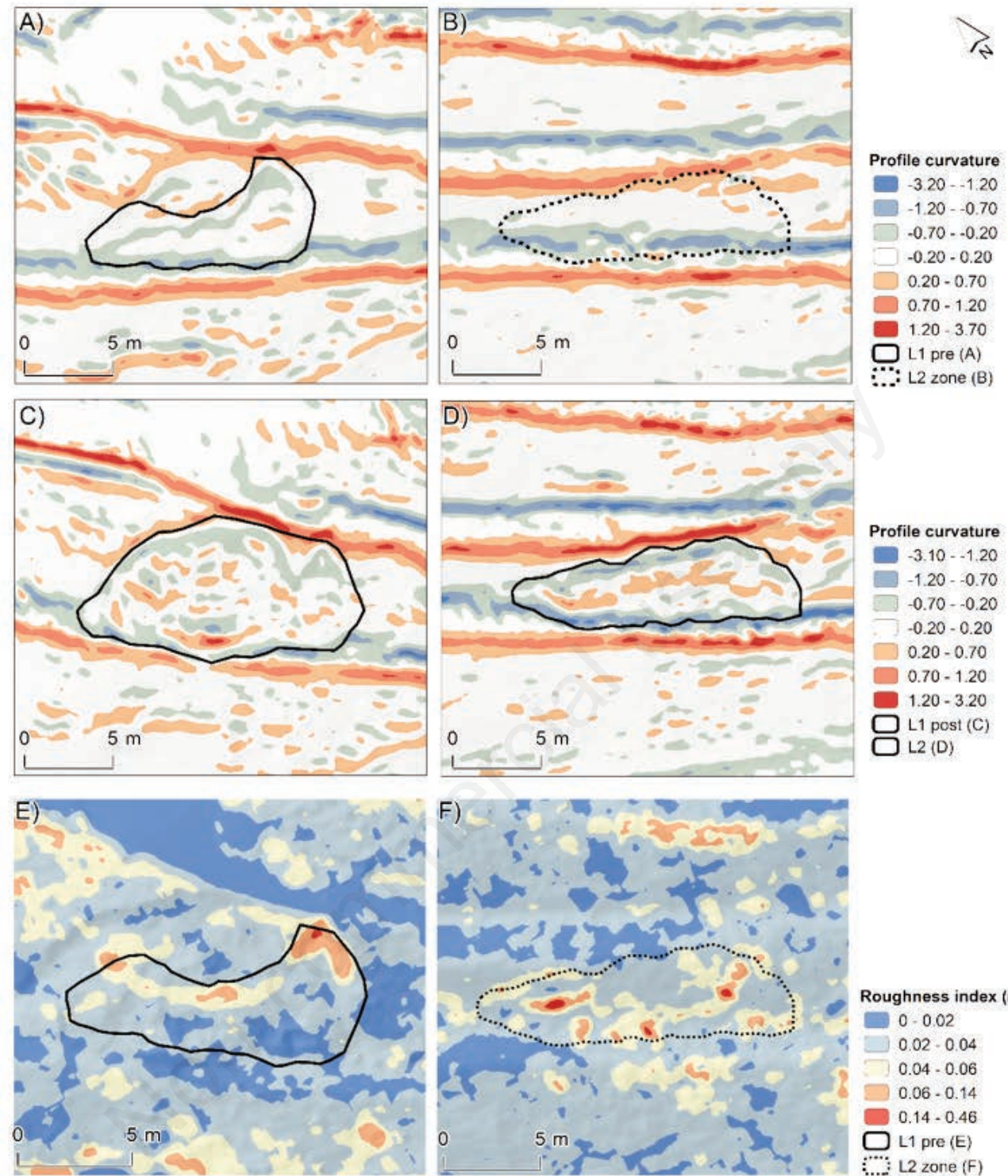

Roughness index (m)

0.0 .02

$0.02 \cdot 0.04$

$0.04 \cdot 0.06$

$\square .06 \cdot 0.14$

$0.14 \cdot 0.46$

$\square$ L1 pre (E)
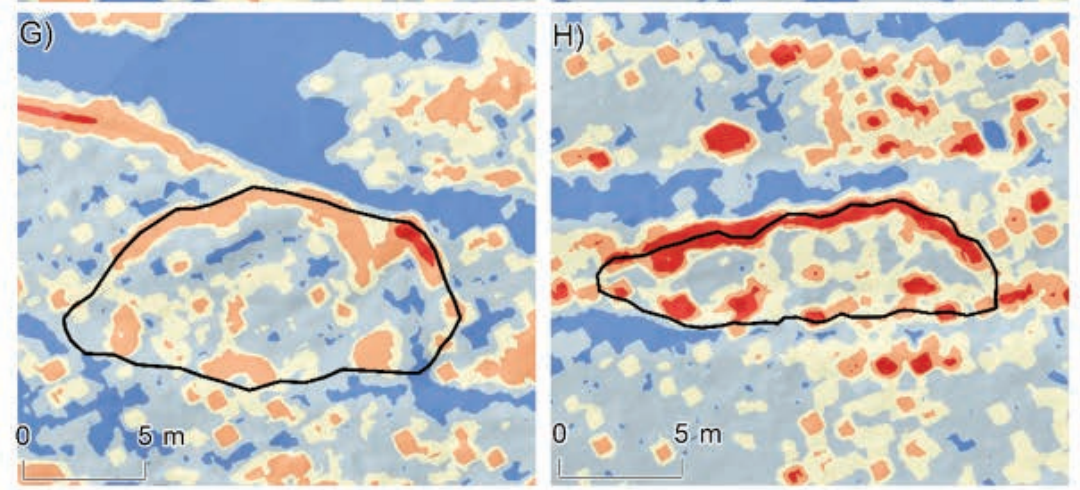

..... L2 zone (F)

Figure 5. Multi-temporal comparison of profile curvature computed for L1-pre (A) and L1-post (C) and for L2 (D). Figure 4B shows the profile curvature elaborated for the zone affected by L2, before its occurrence. This figure also shows the multi-temporal comparison of the roughness index performed for L1-pre (E), L1-post $(\mathrm{G})$ and $\mathrm{L} 2(\mathrm{H})$. Figure 4F shows the roughness index elaborated for the zone affected by L2, before its occurrence. 
maximum slope (Krebs et al., 2015). In Figure 5A and Figure 5C, convex surfaces are identified by the positive values of the profile curvature. The comparison with the profile curvature elaborated for the same landslide area observed during the first UAV survey (i.e., L1-pre) (Figure 5A) highlights the geomorphological changes of the L1 zone. Likewise, the activation of L2 is underlined by the presence of high values of the profile curvature close to it (Figure $5 \mathrm{D})$ with respect to the observations made in the same zone before its activation (Figure 5B). The computation of the profile curvature also shows negative values (blue colours) within each landslide's surface. These values indicate upwardly concave surfaces, which can potentially be deposition areas due to terrain failures and land movement into each landslide zone.

Figure 5 also shows the multi-temporal comparison of the roughness index calculated for L1 and L2. The roughness index calculation as the standard deviation of residual topography allowed us to calculate the surface roughness, which was not affected by the influence of slope variability along the surface. The evolution of L1 and L2 between the two UAV surveys can be recognised through the local variabilities of the elevation values (Figure 5E-H). In the figure above, the higher values of the roughness index can be seen close to the top of the landslides (Figure 5G and $\mathrm{H}$ ), while the concurrent presence of high roughness values upstream and downstream the L2 zone mainly derive from the remaining noises of the residual topography computation. At the same time, lower roughness values correspond to flat areas, such as the road network or the grass surfaces close to the detected landslides.

\section{Multi-temporal feature extraction}

The multi-temporal comparison of maximum curvature and feature extraction for L1 and L2 is outlined in Figure 6.

The evolution of L1 is shown by the elaboration of the curvature and the consequent features extraction. The comparison of the curvature maps elaborated for L1-pre and L1-post (Figure 6A and B) shows an increase of the curvature values, which correspond to the convex slope breaks close to the collapsed terrain. In this regard, the feature extraction using $1.5 \mathrm{IQR}$ as a threshold value successfully describes the evolution of L1 features (Figure 6C and D). Some noises affect the result of feature extraction, and their presence is mainly due to the choice of the $m$ factor (see Equation 7). When this parameter increases, the feature recognition is more efficient with a concurrent reduction of hillslope noises. At the same time, however, exaggerated values of $m$ can lead to the loss of information about the features being extracted (Tarolli et al., 2012).

Likewise, Figure 6E-H shows the multi-temporal mapping of $\mathrm{C}_{\max }$ and the feature extraction for the $\mathrm{L} 2$ zone before and after the landslide occurred. This figure shows an increase of the curvature values upstream the L2 site (Figure 6E and F) and the presence of high $\mathrm{C}_{\max }$ values within the L2 surface with respect to the curvature map elaborated for the same area before L2 activation. The L2-feature extraction highlights the landslide activation, underlining specific convexities that correspond to the extracted features themselves. A low presence of hillslope noises among the detected L2 surface (Figure 6G and $\mathrm{H}$ ) is evident, especially in the L2 area observed during the first UAV survey (Figure 6G). The results indicate an overall consistency between the extracted and the referenced features, with a quality index equal to 0.22 for L1-pre, 0.63 for L1-post, and 0.69 for L2.

Figure 6 shows a multi-temporal comparison between observed and extracted features for L1 and L2. The red arrows in Figure $6 \mathrm{C}, \mathrm{D}$ and $\mathrm{H}$, highlight the match between the detected and extracted features for both L1 and L2. At the same time, this figure also shows the presence of many detected features that were not successfully extracted by the adopted methodology. These areas of mismatch between what was on the field and what was subsequently elaborated in terms of extracted features mainly represent false positives data (i.e., type I errors).

\section{Discussion}

This article proposes an analysis of the monitoring process of shallow landslides activated in a steep terraced agricultural system through an innovative multi-temporal comparison of geomorphometric indicators using a multitemporal survey. Our work further highlights the efficiency of 4D UAV-based SfM surveys in this kind of analysis in line with other useful UAV applications in agricultural contexts (Tucci et al., 2019; Yamazaki et al., 2019). The elaboration of high-resolution DEMs allowed the computation of some key morphometric indexes to better understand the Earth surface physical process considered in our analysis.

The mapping of the RPII index, for example, revealed values between $2 \sigma$ and $4 \sigma$ close to the road sections located above L1 and L2, showing the role played by the road network in the alteration of water flow directions, thus triggering the activation of landslides. Similar analyses were presented in Tarolli et al. (2013), where the RPII was applied in a mountain environment for the detection of surface water flow alteration and erosion due to mountain trails and forest roads, and in Tarolli et al. (2015) for the evaluation of the role of agricultural roads in the activation of soil erosion processes. The novel point of our work is the application of the RPII to multitemporal DEMs to test its predictive capability for shallow landslide phenomena. The obtained results emphasized its efficiency in identifying potentially critical interactions between the road and water directions. This information could be useful for providing effective soil and water conservation measures to mitigate the phenomena (e.g., ditches). Our work also, confirmed the advantages of RPII with respect to other indexes like the index of connectivity (Cavalli et al., 2013) or the simple elaboration of water flow directions. While these latter are useful for detecting sediment connectivity toward specific features and the investigation of unaltered water flow dynamics, the RPII represents a rapid and efficient tool to analyse landslide triggering on terraced agricultural systems.

The DoD elaboration led to a detailed volumetric estimation of erosion and deposition surface close to the collapsed hillslopes. In this connection, our research further highlights that the multiple error assessment in DoD computation can be successfully implemented in the multi-temporal investigation of landslide dynamics affecting very steep terraced agricultural systems at the hillslope scale. Comparable analyses were proposed by Wheaton et al. (2010), Vericat et al. (2017) and Cucchiaro et al. (2018), who investigated different environmental contexts and purposes, focusing on the possibility to adopt a spatially distributed error evaluation in the investigation of geomorphological changes affecting areas with complex topography.

The innovative multi-temporal comparison of profile curvature, roughness and feature extraction proved a valuable tool to describe in-depth the evolutionary dynamics of specific landslide features, such as their crown and other detected geomorphological changes affecting the terraced agricultural area under study on a field scale over time. The UAV-based multi-temporal analysis of shallow landslide crown evolution in a high-steep agricultural 

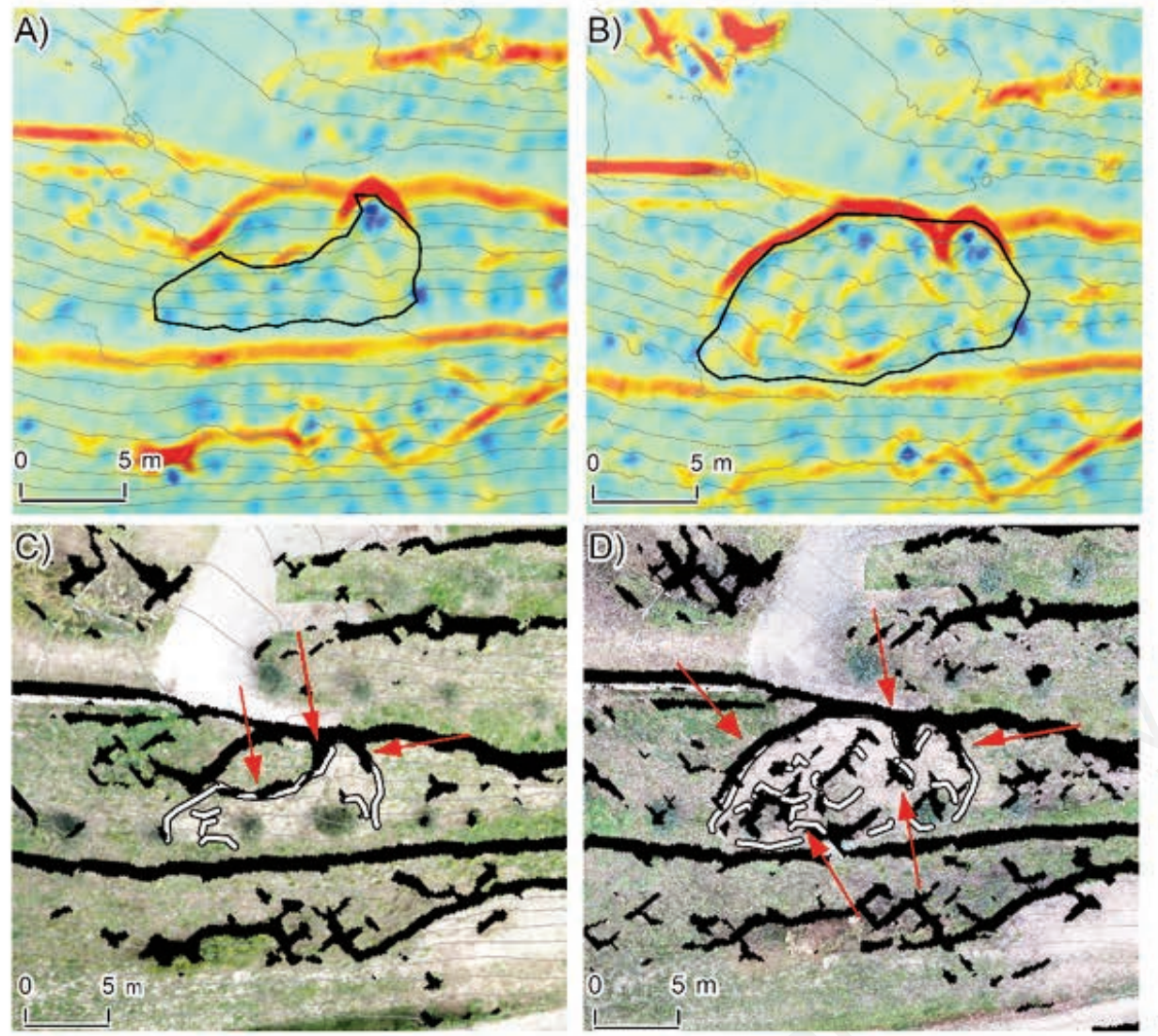

(A) Maximum Curvature $\left(m^{-1}\right)$

- High : 24.6

Low : 5 .

(B) Maximum Curvature $\left(\mathrm{m}^{-1}\right)$

15.5

$-4.6$

Contour line $(1 \mathrm{~m})$

$\square$ (A) L1-pre

$\square$ (B) L1- post

Extracted features Observed features
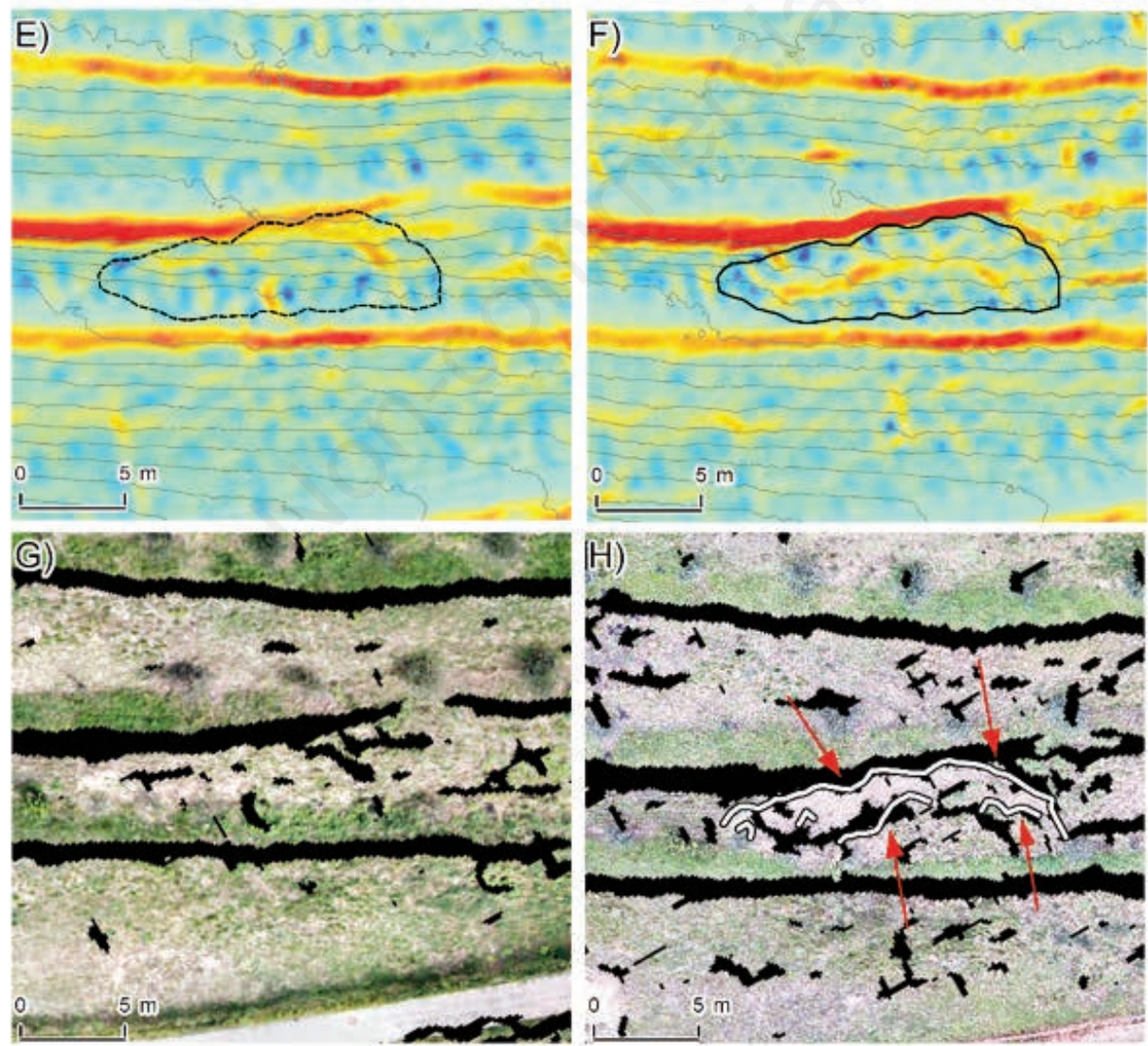

(E) Maximum Curvature $\left(m^{-1}\right)$

$-24.6$

- -5.1

L2 zone

(F) Maximum Curvature $\left(\mathrm{m}^{-1}\right)$

15.5
-4.6
$\square 2$
$\mathrm{~L} 2$
Contour line (1m)
Extracted features
Observed features

Figure 6. Multi-temporal comparison of $\mathrm{C}_{\max }$ computed for L1-pre (A), L1-post (B), L2 zones before (E) and after (F) its occurrence, and multi-temporal comparison between observed and extracted features for L1-pre (C), L1-post (D), L2 zones before (G) and after $(\mathrm{H})$ the failure. The red arrows indicate the position of the extracted features as observed during the field surveys. 
landscape is a novelty that deserves attention for planning useful mitigation strategies. Finally, the computation of the quality index was equal to 0.22 (L1-pre), 0.63 (L1-post), and 0.69 (L2), thus underlining the efficiency of features extraction and further supporting the quality of the presented outcomes and the validity of the adopted methodology. Compared to the results obtained in Tarolli et al. (2012), where landslide crown features were extracted in complex landscapes, the values of the quality index obtained in our work indicate better performance (L1-post and L2). Therefore, this confirms that a UAV-based multi-temporal survey, carried out with proper attention, could be an excellent tool for monitoring landslide occurrence in terraced agricultural hillslopes over time.

\section{Conclusions}

This work proposes a multi-temporal computation of geomorphometric indicators to provide a detailed analysis of the landslide dynamics affecting a very steep slope terraced agricultural system. The focus was on landslides activated by roads. We considered high-resolution digital elevation models derived from two UAV photogrammetry surveys. The $4 \mathrm{D}$ comparison of geomorphometric indicators revealed to be an efficient tool in the study of geomorphological changes at the field scale. The study of this topic through the proposed methodology can be a well-grounded starting point to further investigations on a larger scale. The analyses presented in this work can be seen as a useful tool for mapping landslide phenomena affecting agricultural areas, focusing on the role of road networks in their activation. This topic still needs to be deeply investigated in the literature. The geomorphic indexes tested in the work (RPII, roughness index, landform curvature) and the quantification of the soil eroded and deposited by landslides through the geomorphic change detection approach helped us to better understand (thanks to the details of the considered microtopography) the discussed phenomena in the investigated steep agricultural terraced hillslope. We believe that these findings will provide a basis for additional analysis regarding the influence of road management and design on land degradation dynamics, which are responsible for severe economic losses, geomorphological changes, and environmental alterations of agricultural systems as a whole. In this way, the proposed results and the obtained thematic maps could prove useful to identify and implement sustainable actions for more efficient management of this aspect. Specific interventions on soil management, bank stabilization, and restoration could be carried out starting from the comparison of roughness, curvature, and feature extraction over time to promptly find out efficient mitigation strategies to reduce the occurrence of risk scenarios.

Further investigations could be undertaken to analyse in greater depth this topic in hydrological terms, focusing on the design of alternative drainage systems along the roadway and close to the collapsed surfaces. In this connection, a more extensive scientific knowledge can be gained on the role played by roads in the alterations of superficial and sub-surface water dynamics linked with the occurrence of landslides also in agricultural systems. Moreover, identifying areas that can be potentially exposed to landslide activation represents a relevant aspect for landowners and farmers. Therefore, this has a primary relevance especially where the presence of infrastructures like roads and trails is fundamental in term of productivity and cropland management, but can also represent one of the main causes for landslides and land degradation processes.

\section{References}

Bajocco S., De Angelis A., Perini L., Ferrara A., Salvati L. 2012. The impact of Land Use/Land Cover Changes on land degradation dynamics: A Mediterranean case study. Environ. Manage. 49:980-9.

Borga M., Tonelli F., Selleroni J. 2004. A physically based model of the effects of forest roads on slope stability. Water Resour. Res. 40.

Bordoni M., Vercesi A., Maerker M., Ganimede C., Reguzzi M.C., Capelli E., Wei X., Mazzoni E., Simoni S., Gagnarli E., Meisina C. 2019. Effects of vineyard soil management on the characteristics of soils and roots in the lower Oltrepò Apennines (Lombardy, Italy). Sci. Total Environ. 693:133390.

Bossi G., Cavalli M., Crema S., Frigerio S., Quan Luna B., Mantovani M., Marcato G., Schenato L., Pasuto A. 2015. Multi-temporal LiDAR-DTMs as a tool for modelling a complex landslide: A case study in the Rotolon catchment (eastern Italian Alps). Nat. Hazards Earth Syst. Sci. 15:715-22.

Brasington J., Langham J., Rumsby B. 2003. Methodological sensitivity of morphometric estimates of coarse fluvial sediment transport. Geomorphology 53:299-316.

Cavalli M., Tarolli P. 2011. Application of LiDAR technology for rivers analysis. Ital. J. Engine. Geol. Environ. 1:33-44.

Cavalli M., Trevisani S., Comiti F., Marchi L. 2013. Geomorphometric assessment of spatial sediment connectivity in small Alpine catchments. Geomorphology 188:31-41.

Cucchiaro S., Cavalli M., Vericat D., Crema S., Llena M., Beinat A., Cazorzi F. 2018. Monitoring topographic changes through 4D-structure-from-motion photogrammetry: application to a debris-flow channel. Environ. Earth Sci. 77:632.

Eker R., Aydin A. 2014. Assessment of forest road conditions in terms of landslide susceptibility: A case study in Yığılca Forest Directorate (Turkey). Turkish J. Agricult. Forestry 38:281-90.

Evans I.S. 1979. An integrated system of terrain analysis and slope mapping: Final Report. Geomorphology 36:274-95.

Heipke C., Mayer H., Wiedemann C., Jamet O. 1997. Automated reconstruction of topographic objects from aerial images using vectorized map information. Int. Archiv. Photogramm. Remote Sens. XXXII:47-56.

Krebs P., Stocker M., Pezzatti G.B., Conedera A. 2015. An alternative approach to transverse and profile terrain curvature. Int. J. Geogr. Inf. Sci. 29:643-66.

Lague D., Brodu N., Leroux J. 2013. Accurate 3D comparison of complex topography with terrestrial laser scanner: application to the Rangitikei canyon (N-Z). ISPRS J. Photogramm. Remote Sens. 82:10-26.

Lanni C., Borga M., Rigon R., Tarolli P. 2012. Modelling shallow landslide susceptibility by means of a subsurface flow path connectivity index and estimates of soil depth spatial distribution. Hydrol. Earth Syst. Sci.16:3959-71.

Persichillo M.G., Bordoni M., Cavalli M., Crema S., Meisina C., 2018. The role of human activities on sediment connectivity of shallow landslides. Catena 160:261-74.

Remondino F., Nocerino E., Toschi I., Menna F. 2017. A critical review of automated photogrammetric processing of large datasets. Int. Archiv. Photogramm. Remote Sens. Spatial Inf. Sci. 42:591-9.

Salvati L., Mavrakis A., Colantoni A., Mancino G., Ferrara A. 2015. Complex adaptive systems, soil degradation and land sensitivity to desertification: a multivariate assessment of Italian agro-forest landscape. Sci. Total Environ. 521:235-45. 
Sidle R.C., Ziegler A.D. 2012. The dilemma of mountain roads. Nature 5:437-8.

Sidle R.C., Ziegler A.D., Negishi J.N., Rahim A., Siew R., Turkelboom F. 2006. Erosion processes in steep terrain Truths,myths and uncertainties related to forest management in Southeast Asia. 224:199-225.

Sofia G. 2020. Combining geomorphometry, feature extraction techniques and Earthsurface processes research: the way forward. Geomorphology 355.

Tarolli P., Sofia G., Dalla Fontana G. 2012. Geomorphic features extraction from high-resolution topography: Landslide crowns and bank erosion. Nat. Hazards 61:65-83.

Tarolli P., Calligaro S., Cazorzi F., Dalla Fontana G. 2013. Recognition of surface flow processes influenced by roads and trails in mountain areas using highresolution topography. Eur. J. Remote Sens. 46:176-97.

Tarolli P., Sofia G., Calligaro S., Prosdocimi M., Preti F., Dalla Fontana G. 2015. Vineyards in terraced landscapes: new opportunities from lidar data. Land Degrad. Develop. 26:92102.

Tucci G., Parisi E.I., Castelli G., Errico A., Corongiu M., Sona G., Viviani E., Bresci E., Preti F. 2019. Multi-sensor UAV application for thermal analysis on a dry-stone terraced vineyard in rural tuscany landscape. ISPRS Int. J. Geo-Inf. 8.

Vericat D., Wheaton J. M., Brasington J. 2017. Revisiting the morphological approach: opportunities and challenges with repeat high-resolution topography. In: D. Tsutsumi, J.B. Laronne (Eds.), Gravel-bed rivers: processes and disasters, 1st edn. Wiley, Oxford, pp 121-158.

Webb N.P., Marshall N.A., Stringer L.C., Reed M.S., Chappell A., Herrick J.E. 2017. Land degradation and climate change: building climate resilience in agriculture. Front. Ecol. Environ. 15:450-9.

Wheaton J.M., Brasington J., Darby S.E., Sear D.A. 2010. Accounting for uncertainty in DEMs from repeat topographic surveys: improved sediment budgets. Earth Surf. Process Landf. 35:136-56.

Westoby M.J., Brasington J., Glasser N.F., Hambrey M.J., Reynolds J.M. 2012. Structure-from-Motion' photogrammetry: A low-cost, effective tool for geoscience applications. Geomorphology 179:300-14.

Wilson J.P., Gallant J.C. 2000. Digital terrain analysis, in terrain analysis: principles and applications. John Wiley \& Sons, New Yoyk, NY, USA.

Wood J. 1996. The geomorphological characterisation of digital elevation models. Ph.D. Thesis, University of Leicester, UK.

Yamazaki Y., Okazawa H., Sekiyama A., Fujikawa T. 2019. Accuracy Verification of UAV-SfM survey of terrace paddy fields in a hilly and mountainous area. IJERD Int. J. Environ. Rural Develop. 10:153-9. 